\title{
A Comparative Study on New Product Development Projects: Supplier-client Partnerships in Manufacturing Industry
}

\author{
Vuyo T. Hashe ${ }^{*}$ \\ ${ }^{1}$ Department of M echanical and Industrial Engineering Technology, U niversity of J ohannesburg, \\ South A frica
}

\begin{abstract}
This paper was to investigate, explore and gain an understanding of the factors that enable and support supplier-client collaboration in New Product Development Projects (NPDP) within the South African manufacturing industry. This study was based on two case studies where two NPDP within South African on two different firms were studied. The predominant focus of this report studied the supplier involvement and relationship factors, supplier selection factors, and cultural environment and collaboration factors. The main data used was collected via interviews and internal company documents. The collected data was then analyzed and the outcome provided insight into the factors and relationship between these factors. This study noted that firms can enter into collaboration to accelerate the product development process. This includes enhancing the ability of the firm to respond to key customer needs. Firms can make use of the collaboration advantage where they see a market opportunity where their teams have less to no expertise and skills required to capture the opportunity. In addition, research and development costs stand to be reduced significantly, where the collaboration partner is chosen effectively. This study concludes by seeing it as beneficial to firms to collaborate with their suppliers under proper management.
\end{abstract}

Keywords: buyer, product development, supplier

\section{Introduction}

Collaborations with suppliers in NPDP involves the amalgamation of the buyers and suppliers. Research and development resources together with the expertise and capabilities of each party are synchronized, to allow a strategic integration where both parties establish a solid foundation for an effective working relationship [1]. The buying firm's new product competitiveness is the one that provides support on the supplier's resources. As such, to create internal organization's modest advantage through supplier-client collaboration in NPDP

* Corresponding author: vhashe@uj.ac.za 
requires that the client's firm build up a sustain appropriate practices and processes to enable the selection of the suppliers possessing matching competencies in NPDP [1].

According to Dimancescu and Dwenger [2], many world-class manufacturers have learned to involve suppliers early in the product development process. They understand that leveraging the parent firm's competencies with those of specialized suppliers is one of the keys to building competitive advantage and adding to the agility of the enterprise. The Japanese set out early in the 1950s to build supplier networks, and a growing number of Western-style supplier associations are reaping the benefits. For example, electronics firms in and around Silicon Valley have pioneered a regional supplier agglomeration [2].

Literature from different industries indicates benefits from supplier-client collaboration in generic product development to be significant. Birou and Fawcett [3] and Laura and E [4] argued that there is still an argument between researchers and no conclusions can be reached yet. They assert that buyers can benefit from involving suppliers early in the development process. The benefits include effective and efficient support in areas where it comes to timeto-market of new products. In addition, product quality can be improved with savings on development cost and the overall product cost. Supplier-client collaboration is reported as beneficial to the buying firm $[4,5]$. The buying firm stands to gain new competencies with shared risks, quick market penetration and time-to-market shortened, and resources conservation is likely to be seen.

According to Takeishi [6] companies that go on partnerships in NPDP with their suppliers do so in order to gain access to the supplier's technology. The partnership agreements are most likely to include shared responsibilities and risk for design and development patents.

\section{Literature reviews}

There are multiple aspects to the requirements of successful collaboration. The literature identifies these to be divided into three sections. The first section covers supplier involvement and relationship factors. This area covers the factors that are supportive of collaborative efforts and the impact of these relationships. The second section covers the supplier selection factors, these are necessary before deciding to enter into an agreement to collaborate. Ensuring that the right partner is selected is vital and this is supported by the literature. The third section covers the cultural environment and collaboration. The understanding of the culture of an organization and country could affect collaboration and it is important to understand it. Collaboration is often referred to as strategic partnerships between supplier and client. Literature covers collaboration (or partnership) under various names and in this paper, the author investigated to understand the environmental and driving factors.

\subsection{Earlier research}

\subsubsection{The 1980s}

The first research said to have focused specifically on supplier involvement in NPDP was the study by Takeuchi and Nonaka [6] in 1986. This research contribution was based on Japanese companies looking at the same set of seven case studies. They looked at dedicated suppliers describing their commitment to supplier networks. They also went on to explain the superior performance by suppliers in NPDP.

\subsubsection{The 1990s}

A few more studies followed in the 1990s with the findings in the automotive industry analyzing the involvement of supplier in NPD. As the process goes on approaching the 
middle of the 1990s, research saw a move away from the automotive industry. A study by Bonaccorsi and Lipparini [8] appeared in the form of a case study at a food processing and packaging company in Italy where Bonaccorsi and Lipparini [8] saw benefits in the partnership. Eisenhardt and Tabrizi [9] published one non-automotive study which became one of the first non-automotive studies indicating that if technological uncertainty is obvious then fewer suppliers in the partnership is critical.

Hartley and colleagues [10] in their study concluded that collaboration involving product design engineers and engineering managers in assembly industries can add value if managed effectively

\subsubsection{The 2000s}

In NPDP where supplier selection and assessment was one element recommended dominates the literature [11]. However, a recent review by Johnsen [12] shows conflicting results with regards to technological uncertainty in supplier involvement in NPDP. Supplierclient partnerships research at the beginning and during the year 2000 has further looked at the need to establish relationships and adaptation especial in conditions where there is technological uncertainty [11]. This implies that firms should be careful when selecting suppliers to New Product Development projects where there are technological uncertainties.

\section{Methodology}

This paper was prepared to investigate and understand the phenomenon of supplier involvement in NPDP with the intention of gaining access to their technology. The available literature in the supply chain regarding this subject, in general, have compiled with less written about criteria for supplier involvement and relationship factors, supplier selection, and cultural environment and collaboration in NPDP. The methodology followed in this paper is as suggested by [13]. Melander [13] attest that a case study is a phenomenon and is recommended for the study of a complex unit with multiple variables especially in trying to understand a phenomenon. The logical approach to this work is presented in Fig 1.

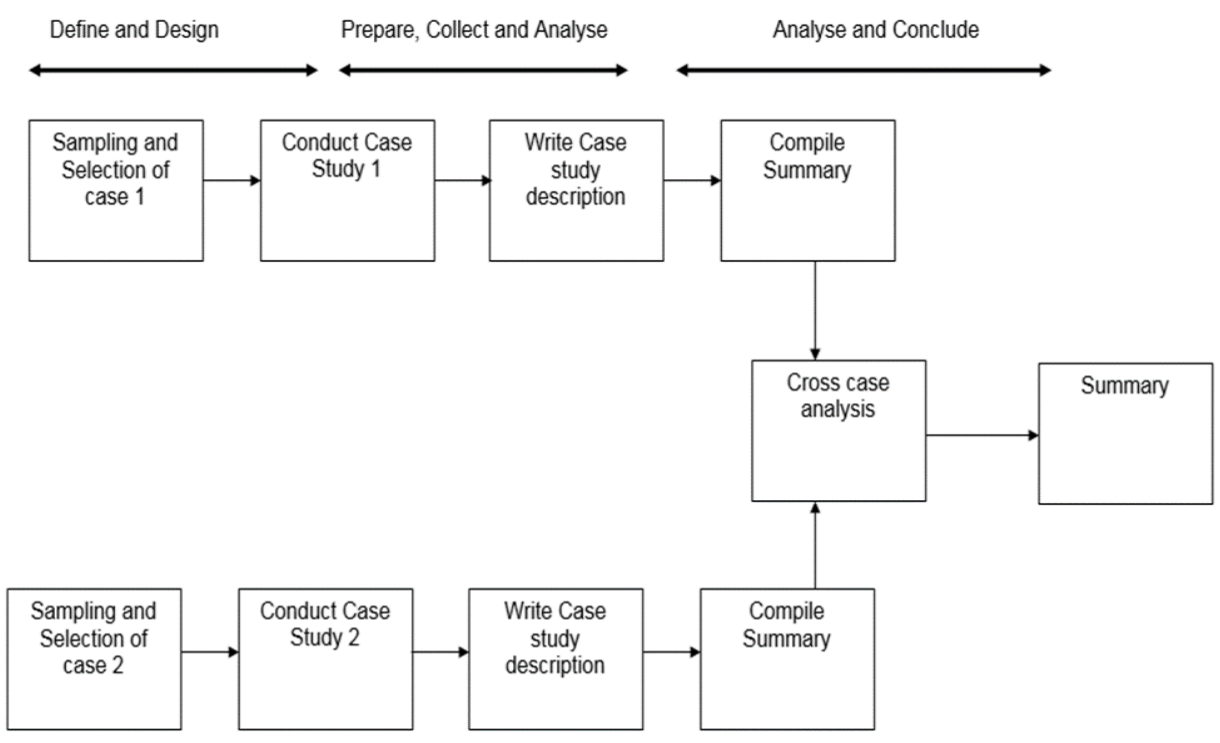

Fig. 1 Research Design (M odified from [13]) 


\section{Case Studies}

Both cases studied in this paper were surveying studies and both were initiated at the end phase of two separate NPDP. The end phase is the phase during which the projects were being finalized. This work started with a single case and thereafter one more case study was added. According to [14] a single case study would have been enough where the context is purely for understanding and has been properly selected.

Table 1 presents an overview of the two case studies. Both these case studies are conducted at different organisations, located in different areas within the Gauteng Province in South Africa. The two case studies have similarities with regards to company culture and location. Moreover, both cases involve a product that is important to the firm, as well as the inclusion of technology that is new to the firm and is delivered by an external supplier.

Table 1. Case study description

\begin{tabular}{ccc}
\hline & Case 1 & Case 2 \\
\hline P P d duration & Pumps & Filters \\
Industry & 2 years & 1 year \\
Technology & Mining, water and municipal & $\begin{array}{c}\text { A utomotive, mining, } \\
\text { construction }\end{array}$ \\
Technology uncertainty & Pump & Filter \\
Degree of innovation & High & L ow \\
No of supplier involved & High & L ow \\
& Two & one
\end{tabular}

\subsection{Data Collection}

Data collection was conducted by the form of interviews, internal and external documents, brochures, company web pages, factory visits, and technical documents. The most consistent and relevant data were obtained from interviews. The interviews focused mainly on individuals involved in the NPDP. An interview guide with interview questions and the main topics for discussion was prepared. Additional follow-up questions were also noted. The interviews in this study were conducted in group interviews during NPDP meetings and also with face-to-face. One-on-ones were conducted in order to gain an individual's views assuming that some individuals may not be comfortable in speaking their views freely. Table 2 presents the interview overviews.

The questionnaire is aimed at collecting information on the factors that would lead to the formation of collaborative relationships in organizations and focused on three areas. The interview questions were developed based on literature review and were asked from the participants during interviews. The idea was to ask the respondents the questions and rate their answers to determine the negative as well as positive aspects. The three areas are cultural and demographic factors, the extent of collaboration, decision factors (supplier selection) for engaging with other organizations. 
Table 2. interview overviews

\begin{tabular}{|c|c|c|c|c|}
\hline Case & $\begin{array}{c}\text { No. of } \\
\text { interviews }\end{array}$ & Team members & $\begin{array}{c}\text { Interview } \\
\text { duration }\end{array}$ & Time period \\
\hline Case 1 & 6 & $\begin{array}{c}\text { Design Engineer, Project } \\
\text { M anager, Draughtsman, } \\
\text { Foundry Engineer, Q uality } \\
\text { Engineer, Foundry } \\
\text { Technician }\end{array}$ & 10 hours & 4 months \\
\hline Case 2 & 3 & $\begin{array}{c}\text { Product } M \text { anager, } \\
\text { Engineering } M \text { anager, } \\
\text { Sales Engineer, B uying } \\
\text { M anager, Sales } \\
\text { Representative }\end{array}$ & 12 hours & 6 months \\
\hline
\end{tabular}

\subsection{Data analysis}

The collected data was analyzed, hence the data was organized, divided and categorized. Eisenhardt [15] pointed out that cross-case analysis is preferable when studying case studies, however, the researcher should be well familiar with each case. For this purpose, the matrix for comparison was identified and presented in Table 3. This matrix focused on the similarities and differences of both organisations in partnership.

Table 3. Matrix for comparison

\begin{tabular}{|c|c|c|}
\hline $\begin{array}{l}\text { Purchasing's } \\
\text { Involvement }\end{array}$ & Case 1 & Case 2 \\
\hline Similarities & $\begin{array}{c}\text { Buying firm has a } \\
\text { Purchasing department } \\
\text { No participation in the technology } \\
\text { selection }\end{array}$ & $\begin{array}{l}\text { B uying firm has a Purchasing } \\
\text { department } \\
\text { No participation in the technology } \\
\text { selection }\end{array}$ \\
\hline Differences & $\begin{array}{l}\text { No member from the Purchasing } \\
\text { department in the project team } \\
\text { Purchaser did not have prior } \\
\text { knowledge of the supplier } \\
\text { No participation in the supplier } \\
\text { selection }\end{array}$ & $\begin{array}{l}\text { No member from the Purchasing } \\
\text { department in the project team } \\
\text { Purchaser had prior knowledge of } \\
\text { the supplier } \\
\text { Participation in the supplier } \\
\text { selection }\end{array}$ \\
\hline
\end{tabular}

\subsection{Results}

The total number of people interviewed was 47, some were interviewed in groups and others on one-on-one as indicated in table 2 . Below results are as per questions answered by each correspondent. For this paper, only the key questions answers are shown. 


\subsubsection{Demographic and Cultural Factors}

A number of years in operation: Both companies have been in existence since the 1800 s and their suppliers with an average 40 years in operation and an average 12.5 years dealing with each other. A number of employees in the organization: Both companies are in the employment of over 30000 people worldwide and their suppliers are at an average of 5000 employees each. Expenditure on suppliers and sales revenue: Both companies reflected that they have spent $18 \%$ on average of their turnover on suppliers. The physical distance between supplier and client: The average distance between the main supplier and the customer 230 $\mathrm{km}$ for both cases

Table 4. Frequency of communication

\begin{tabular}{cc}
\hline Very high & $21.2 \%$ \\
High & $49.1 \%$ \\
Neutral & $5.6 \%$ \\
L ow & $19.7 \%$ \\
Very low & $4.4 \%$ \\
Total & $100 \%$ \\
\hline
\end{tabular}

Table 4 presents the results obtained regarding the frequency of communication between partners.

\subsubsection{Collaboration Factors}

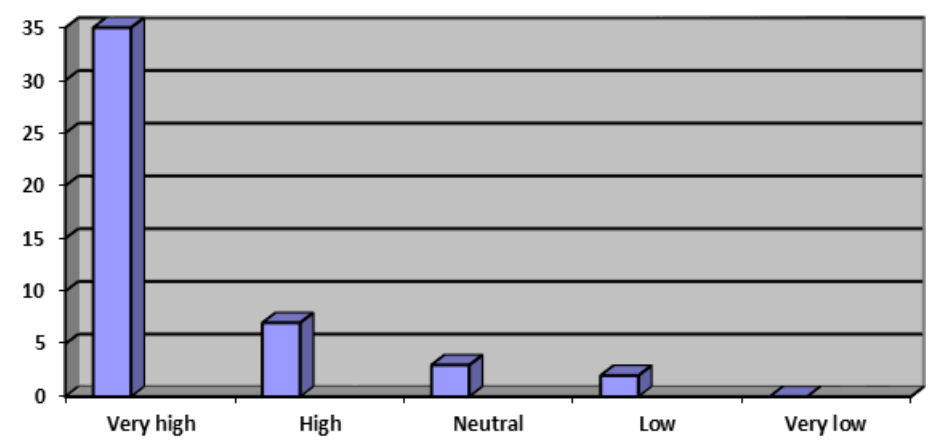

Fig. 1 In your view was collaboration successful?

The $74.47 \%$ indicates that most correspondents viewed collaboration as it was successful.

Table 1. Supplier Involvement in the early planning stages

\begin{tabular}{cc}
\hline Very high & $7.2 \%$ \\
High & $34.5 \%$ \\
Neutral & 14.7 \\
Low & $26.4 \%$ \\
Very low & 17.2 \\
Total & $100 \%$ \\
\hline
\end{tabular}

The results to this question indicate a proportion of almost equal high and low involvement in the planning stages of the business 
Table 6. J oint problem solving - the extent of joint problem solving

\begin{tabular}{cc}
\hline V ery high & $17.2 \%$ \\
High & $48.3 \%$ \\
Neutral & $29.4 \%$ \\
Low & $15.4 \%$ \\
Very low & $5.1 \%$ \\
Total & $100 \%$ \\
\hline
\end{tabular}

\subsubsection{Supplier Selection Factors}

Table 7. Supplier design and manufacturing capabilities

\begin{tabular}{cc}
\hline V ery important & $40.2 \%$ \\
Important & $35.8 \%$ \\
Neutral & $12 \%$ \\
Low important & $12 \%$ \\
N ot Important & $0.0 \%$ \\
Total & $100 \%$ \\
\hline
\end{tabular}

Supplier design and manufacturing capabilities appeared (Table 7) to be one of the factors used for strategic fit used by the two organizations.

Table 8. History on development costs, speed and competitiveness

\begin{tabular}{cc}
\hline V ery important & $53 \%$ \\
Important & $42 \%$ \\
N eutral & $5 \%$ \\
Low important & $0.0 \%$ \\
N ot I mportant & $0.0 \%$ \\
Total & $100 \%$ \\
\hline
\end{tabular}

Table 8 indicates that all parties in partnership understood the importance of competitiveness in the industry.

Table 9 shows that an overwhelming majority of respondents felt that collaboration had a positive impact on the product development partnership.

Table 2. Overall demographic, cultural factors and collaboration factors results (combined)

\begin{tabular}{c|cc}
$\begin{array}{c}\text { Collaboration Factors in General } \\
\begin{array}{c}\text { Product devel opment process more } \\
\text { efficient }\end{array}\end{array}$ & \% A gree (strongly) & \%D isagree (strongly) \\
$\begin{array}{c}\text { An effective and efficient way to better } \\
\text { respond to customer needs }\end{array}$ & 68 & 4 \\
$\begin{array}{c}\text { Quick reaction to market opportunities } \\
\begin{array}{c}\text { Low levels of commitment from one of } \\
\text { the parties cause conflict and frustration }\end{array}\end{array}$ & 69 & 4 \\
$\begin{array}{c}\text { Product risks becoming more specified to } \\
\text { a single customer's needs rather to a } \\
\text { broader target market }\end{array}$ & 64 & 15 \\
$\begin{array}{c}\text { Possible further partnerships for the future } \\
\text { after current partnership expired }\end{array}$ & 58 & 24
\end{tabular}


Risk of possible competition on the same product or similar product/service

Risk of losing proprietary information/ leaking

Partnership easy to manage

The process often stalls and cause to the long development process

Costing is viewed too high in partnerships

\section{Findings and discussion}

This paper was conducted to furthermore contribute to the field by providing an additional study where supplier selection is viewed from the perspective of both the buying firm and the supplying firm. It has been realized from this study that supplier selection criteria are divided into three areas:

- Basic criteria - what the firm considers to be the minimum number of criteria met for a firm to be considered as a future collaborator in NPD.

- $\quad$ Product criteria - those that evaluate the technology or product of the supplying firm

- $\quad$ Firm criteria - includes a number of criteria that assess the supplier according to its management and organization technology.

The basic criteria ensure that the supplying firm fulfils the minimum criteria for collaboration partners. The product criteria evaluate the product and the firm's technical expertise within the chosen technology. Lastly, the supplying firm's characteristics are assessed.

Results show that the majority of the interviewed individuals felt that the supplier-client partnership yielded a positive impact and enhanced the process efficiency $[12,16,17]$.

Respondents noted that the partnership often focuses too much detail to a point where the product becomes too specific to one customer rather than to a whole targeted market. The issue of organizational culture has an effect on successful collaboration proved to be correct. Participants noted that the culture of an organization is vital towards the strategic fit of a supplier within a buying organization. Trust, communication and commitment are seen as the basic requirements towards collaborative culture and ease towards fitting in of two organization. This is to ensure that what is said to be confidential stays confidential.

\section{Conclusion}

The South African manufacturing industry is currently faced with challenges that include low economic growth and shortage of skills in order to compete effectively in the global markets. Companies have to constantly look at ways to which they can cut down of unnecessary spending, non-value adding operations, staff and other means to reduce their operating costs. To tap into the new technology, the South African manufacturing companies need to focus their attention on attracting the technologically frenzy suppliers into strategic partnerships. To do this, it is essential for companies to investigate so to understand the pros and cons that come with such partnerships. The supplier-client partnership goes beyond the transactions in an attempt to collaborate. Firms have to be aware of and understand the importance of the factors associated with supplier-client collaboration. 
Studies on NPDP are reported to have been largely done in the developed countries within the technology-intensive industries. The key contribution of this paper is that it shows that companies are faced with challenging and pressured economic landscape. If companies in South Africa need to invest in supplier-client partnerships, they need to be aware of the factors associated with collaborations and not only the transaction and contracts.

This paper also shares a light regarding the dynamics of collaboration within the South African context. Managers across the manufacturing industry would need to fully understand the complexities and the importance of various factors in ensuring successful suppler-client partnerships. About $75 \%$ of the correspondents participated in this study view collaboration as beneficial to their organizations. Participants also indicated an accelerated product development process where customer requirements are fully attended. The gap in expertise and skills between the parties in the partnership was addressed better with effective leadership in place. The overall research and development costs decreased and the development time reduced significantly. Lack of commitment from one of the partners causes delays and frustration and penalties needed to be set out for defaulters

\section{Reference}

1. J.H. Dyer, H. Singh, The Relational View: Cooperative Strategy and Sources of Interorganizational Competitive Advantage, The Academy of Management Review 23:660-679 (1998)

2. D. Dimancescu, K. Dwenger, World-class New Product Development: Benchmarking Best Practices of Agile Manufacturers, A M A COM (1996)

3. L.M. Birou, S.E. Fawcett, Supplier Involvement in Integrated Product development: A comparison of US and European Practices, International Journal of Physical Distribution and Logistics Management 24(5):4-14 (1994)

4. B. Laura, F.S. E., Supplier Involvement in Integrated Product Development: A Comparison of US and European Practices, International Journal of Physical Distribution \& Logistics Management 24:4-14 (1994)

5. P. Shum, G. Lin, A world class new product development best practices model, International Journal of Production Research 45:1609-1629 (2007)

6. A. Takeishi, Knowledge Partitioning in the Interfirm Division of Labor: The Case of A utomotive Product Development, Organization Science 13:321-338 (2002)

7. H. Takeuchi, I. Nonaka, The N ew New Product Development Game, Harvard Business Review 64 (1986)

8. A. Bonaccorsi, A. Lipparini, Strategic partnerships in new product development: A n Italian case study, Journal of Product Innovation Management 11:134-145 (1994)

9. Eisenhardt, K. M. \& Tabrizi, B. N. 1995. A ccelerating A daptive Processes: Product Innovation in the Global Computer Industry. Administrative Science Quarterly 40:84110.

10. J.L. Hartley, B.J . Zirger, R.R. K amath, M anaging the buyer-supplier interface for ontime performance in product development, Journal of Operations Management 15:5770 (1997)

11. G.L. Ragatz, R.B. Handfield, T.V. Scannell, Success Factors for Integrating Suppliers into New Product Development, Journal of Product Innovation Management 14:190202 (1997)

12. T.E. J ohnsen, Supplier involvement in new product devel opment and innovation: Taking stock and looking to the future, Journal of Purchasing and Supply Management, 15:187197 (2009) 
13. L. M elander, Supplier Involvement in New Product Development under Technological Uncertainty, Doctoral thesis, comprehensive summary, Linköping University Electronic Press, 1568 (2014)

14. A. Dubois, L.E. Gadde, Systematic combining: An abductive approach to case research, Journal of Business Research 55:553-560 (2002)

15. K.M. Eisenhardt, Building Theories from Case Study Research, The Academy of Management Review 14:532-550 (1989)

16. K. Peterson, R. Handfield, G. Ragatz, Supplier integration into new product development: coordinating product, process and supply chain design, Journal of Operations Management 23(3-4):371-388 (2005)

17. M. Hoegl, S.M. W agner, B uyer-supplier collaboration in product development projects, Journal of Management 31(4):530-548 (2005) 